\title{
DESENVOLVIMENTO INICIAL DE PHYSALIS ANGULATA OSMOCONDICIONADA SUBMETIDA AO ESTRESSE SALINO
}

\author{
Josandra Souza Teles Fonseca $^{{ }^{1} \text {; Claudinéia Regina Pelacani }}{ }^{2}$; Natália dos \\ Santos Barroso $^{3}$ e Laura Carolina da Silva Rodrigues ${ }^{4}$ \\ 1. Bolsista PIBIC/ FAPESB, Graduando em Agronomia, Universidade Estadual de Feira de \\ Santana, e-mail: josandrateles@hotmail.com \\ 2. Orientadora, Departamento Ciências Biológicas, Universidade Estadual de Feira de Santana, e-mail: \\ claudineiapelacani@gmail.com \\ 3. Doutoranda, Recursos Genéticos Vegetais Universidade Estadual de Feira de Santana, e-mail: \\ nataliasbarroso@yahoo.com.br \\ 4. Graduanda em Agronomia, Universidade Estadual de Feira de Santana, e-mail: \\ lauracrodrigues@hotmail.com.br
}

PALAVRAS-CHAVE: Physalis;Salinidade;Osmocondicionamento .

\section{INTRODUÇÃO}

Com aproximadamente 120 espécies distribuídas principalmente nas Américas Central e do Sul, o gênero Physalis é caracterizado por produzir compostos com atividades biológicas. $P$. angulata, também conhecida como Camapú, é bastante utilizada na medicina popular por possuir atividade antibacteriana, anti-fúgica e leishimanicida, já comprovada (LEE et al., 2009).

As sementes de Physalis apresentam alto poder germinativo. Entretanto a germinação pode ser afetada pela alta salinidade dos solos, causando reduções no potencial osmótico do solo dificultando assim a embebição das sementes, bem como devido ao acúmulo de determinados íons no protoplasma da semente (MUNNS, 2005).

Em sementes envelhecidas e deterioradas as membranas celulares de sementes são mais sensíveis aos danos de embebição e estresses abióticos, pois estas já estão enfraquecidas, perdem sua integridade e tornam-se mais suscetíveis à rápida entrada de água. Para que a regulação da entrada de água na semente aconteça, o uso de substâncias químicas osmoticamente ativas tem sido amplamente utilizado como forma de controle da entrada de água e tem se mostrado uma importante "ferramenta" para a produção de certas culturas. (SANTOS, 2008). O condicionamento osmótico é um tratamento que apresenta respostas positivas no revigoramento de sementes de $P$. angulata, proporcionando incremento na germinação de sementes, bem como a tolerância à salinidade, contribuído para a manutenção de uma alta taxa de germinação em concentrações salinas elevadas (SOUZA et al., 2016).

Nesse contexto, os estudos fisiológicos em sementes de Physalis angulata, poderam ampliar o entendimento de como esta espécie de responde a tais condições. Assim, o presente trabalho teve como objetivo avaliar os efeitos da salinidade na germinação e na formação de plântulas de Physalis angulata sob efeito do osmocondicionamento.

\section{MATERIAL E MÉTODOS}

Sementes de Physalis angulata produzidas e beneficiadas em 2010, 2013, 2014 e 2015, no Horto Florestal da Universidade Estadual de Feira de Santana foram mantidas em geladeira até o inicio dos ensaios no Laboratório de Germinação (LAGER/HORTO/UEFS). 
Para avaliar o efeito do osmocondicionamento de sementes no crescimento inicial das plântulas de Physalis angulata frente ao estresse salino, foram utilizadas sementes em duas condições: osmocondicionadas e não osmocondicionadas. As amostras de sementes de cada acesso (1.000 sementes) foram colocadas em tubo de ensaio, contendo $25 \mathrm{ml}$ de solução de polietilenoglicol (PEG 6000) (VILELA et al. 1991) preparado a -1,2 $\mathrm{MPa}$, cujo potencial osmótico foi previamente estabelecido como potencial de priming da espécie (SOUZA, 2009). Os tubos foram conectados a um sistema de aeração artificial (bomba de aquário). As sementes foram condicionadas nesta solução em câmara de germinação ajustada a $35^{\circ} \mathrm{C}$, durante 10 dias (SOUZA, 2009).

Após lavagem e secagem, as sementes osmocondicionadas e não sosmocondiconadas foram dispostas em papel $(28$ x $30 \mathrm{~cm})$ umedecidos com água deionizada (tratamento controle) e dois níveis de salinidade, 10 e $16 \mathrm{dS} \mathrm{m}^{-1}$, soluções preparadas com $\mathrm{NaCl}$. Os rolos foram acondicionados em sacos plásticos fechados durante todo o período experimental e mantidas em BOD, 12 horas de luz a T de $35^{\circ} \mathrm{C}$. Foram utilizadas 4 repetições por tratamento sendo a parcela constituída de 50 sementes. Foram realizadas duas avaliações: aos 7 e 14 dias após a semeadura. Na primeira avaliação foram consideradas sementes germinadas aquelas com emissão da radícula e os valores médios expressados em \%. Na segunda avaliação além do número total de sementes germinadas foram obtidos a \% de plântulas normais (Brasil, 2009).

$\mathrm{O}$ delineamento experimental adotado foi o inteiramente casualizado. Com os dados de porcentagem de germinação e plântulas normais foram construídos tabelas com teste de média. Os dados foram submetidas a análise de variância e as médias comparadas por teste de Tukey em nível de 5\% de probabilidade e teste T de student, utilizando o programa computacional SISVAR (Ferreira, 2011).

\section{RESULTADOS E DISCUSSÃO}

As tabelas 1 e 2 mostram os resultados obtidos do teste de média da germinação de sementes de diferentes acessos da espécie de $P$. angulata, osmocondicionadas e não osmocondionadas, submetidas a diferentes concentrações de salinidade. Observou-se que houve um decréscimo da porcentagem de germinação de sementes de $P$. angulata osmocondicionadas e não osmocondicionadas, à medida que aumentou a salinidade do meio. Condutividade elétrica superiores a $10 \mathrm{dS} . \mathrm{m}^{-}{ }^{1}$, as sementes osmocondicionadas dos acessos mais velhos apresentaram maiores taxas de germinação, e maior velocidade do processo, obtendo-se altas porcentagens de germinação aos 7 dias após a incubação. Para as sementes obtidas mais recentemente, acesso 2015, o osmocondicionamento não influenciou no processo germinativo mesmo quando a CE era de $10 \mathrm{dS} . \mathrm{m}^{-1}$, causando efeito contrário de diminuição na germinação quando o meio salino era aumentado (16 dS. $\left.\mathrm{m}^{-1}\right)$.

Tabela 1 - Porcentagem de germinação e plântulas normais de acessos de sementes de Physalis angulata osmocondicionadas dos acessos 2010, 2013, 2014 e 2015, submetidas a diferentes concentrações salinas. Avaliações realizadas aos 7 e 14 dias após semeadura. 


\begin{tabular}{|c|c|c|c|}
\hline Acessos & $\mathrm{dS} . \mathrm{m}^{-1}$ & 7 dias & 14 dias \\
\hline \multirow[t]{3}{*}{2010} & 0 & $46.5 \mathrm{a}$ & $79.5 a$ \\
\hline & 10 & $55 \mathrm{a}$ & $62.5 \mathrm{a}$ \\
\hline & 16 & $1.5 \mathrm{~b}$ & $10 \mathrm{~b}$ \\
\hline \multirow[t]{3}{*}{2013} & 0 & $99 \mathrm{a}$ & $99 a$ \\
\hline & 10 & $70 \mathrm{~b}$ & $85.5 b$ \\
\hline & 16 & $12.5 \mathrm{c}$ & $80.5 b$ \\
\hline \multirow[t]{3}{*}{2014} & 0 & $96 \mathrm{a}$ & $100 \mathrm{a}$ \\
\hline & 10 & $89.5 \mathrm{a}$ & $99.5 \mathrm{a}$ \\
\hline & 16 & $57.5 \mathrm{~b}$ & $80.5 \mathrm{~b}$ \\
\hline \multirow[t]{3}{*}{2015} & 0 & $93.5 \mathrm{a}$ & $98 \mathrm{a}$ \\
\hline & 10 & $92.5 \mathrm{a}$ & $91 \mathrm{a}$ \\
\hline & 16 & $0 \mathrm{~b}$ & $48.5 \mathrm{~b}$ \\
\hline
\end{tabular}

Tabela 2 - Porcentagem de germinação e plântulas normais de acessos de sementes de Physalis angulata não osmocondicionadas, dos acessos 2010, 2013, 2014 e 2015, submetidas a diferentes concentrações salinas. Avaliações realizadas aos 7 e 14 dias após semeadura.

\begin{tabular}{|c|c|c|c|}
\hline Acessos & $\mathrm{dS} . \mathrm{m}^{-1}$ & 7 dias & 14 dias \\
\hline \multirow[t]{3}{*}{2010} & 0 & $45 a$ & $73 a$ \\
\hline & 10 & $9.5 b$ & $35.5 b$ \\
\hline & 16 & $0 b$ & $0 \mathrm{c}$ \\
\hline \multirow[t]{3}{*}{2013} & 0 & $70 a$ & $91 \mathrm{a}$ \\
\hline & 10 & $5 b$ & $31 b$ \\
\hline & 16 & $1.5 b$ & $17 \mathrm{c}$ \\
\hline \multirow[t]{3}{*}{2014} & 0 & $99.5 \mathrm{a}$ & $99.5 \mathrm{a}$ \\
\hline & 10 & $90.5 b$ & $92 \mathrm{ab}$ \\
\hline & 16 & $90.5 b$ & $78.5 \mathrm{~b}$ \\
\hline \multirow[t]{3}{*}{2015} & 0 & $94 \mathrm{a}$ & $98.5 \mathrm{a}$ \\
\hline & 10 & $79 \mathrm{~b}$ & $98.5 \mathrm{a}$ \\
\hline & 16 & $16.5 \mathrm{c}$ & $53.5 \mathrm{~b}$ \\
\hline
\end{tabular}

Esses resultados indicam que a técnica do osmocondionamento só apresenta efeitos positivos em sementes de $P$. angulata armazenadas por certo período de tempo e 
suficiente em causar algum tipo de diminuição da viabilidade das sementes armazenadas. O mesmo foi observado em trabalhos são citados por Sune et al. (2002), no qual os efeitos do condicionamento osmótico proporcionou a melhoria da velocidade e uniformidade de germinação de sementes de diversas hortícolas. Os resultados de germinabilidade em acessos de sementes menos vigorosas responderam de forma esperada ao osmocondicionamento mesmo na presença da solução salina.

\section{CONSIDERAÇÕES FINAIS}

O osmocondicionamento pode ser utilizado para favorecer a cinética de germinação de acessos menos vigorosos e contribuir para a renovação e o uso de coleções de sementes de $P$. angulata.

\section{REFERÊNCIAS}

BRASIL. Ministério da Agricultura, Pecuária e Abastecimento. Regras para análise de sementes. Brasília: Mapa/ACS, 2009. 399p.

BURGASS, W. R.; POWELL, A.A. Evidence for repair process in the invigoration of seeds by hydration. Annals of Botany, London, v.53, n.5, p.753-757, 1984.

CARVALHO, N.M.; NAKAGAWA, J. Sementes: ciência, tecnologia e produção. 4 nd ed. Jaboticabal, FUNEP, 2012. 588p.

FERREIRA D.F. Sisvar: a computer statistic alanalysis system. Ciencia Agrotecnologia v 35, 1039-1042. 2011.

LEE, H.Z., LIU, W.Z., HSIEH, W.T., TANG, F.Y., CHUNG, J.G., LEUNG, H.W.C.

Oxidative stress involvement in Physalis angulata-induced apoptosis in human oral cancer cells. Food and Chemical Toxicology 47, 561-570, 2009.

MUNNS, R. 2005. Genes and salt tolerance: bringing them together. New Phytologist 167, 45- 663.

ROCHA, G. R. Efeito da temperatura e do potencial hídrico na germinação de sementes de doze cultivares de Feijão- Mungo- Verde Vigna radiata (L.) Wilczek]. JaboticabalSP.Trabalho apresentado à Faculdade de Ciências Agrárias e Veterinárias- UNESPpara graduação em Agronomia, 1996.

SANTOS, Maria Célia Aroucha et al. Condicionamento osmótico de sementes. Revista Caatinga, v. 21, n. 2, p. 1-6, 2008.

SOUZA, C.L.M. Germinabilidade de sementes de Physalis angulata L. (Solanaceae) sob condições de estresses abióticos. Dissertação de Mestrado. Universidade Estadual de Feira de Santana, Feira de Santana, 2009.

SOUZA, M. O. DE; PELACANI, C. R.; WILLEMS L. A. J.; , DE CASTRO , R. D.; HILHORST, H. W.M. ; LIGTERINK W. Effect of osmopriming on germination and initial growth of Physalis angulata L. under salt stress and on expression of associated genes. An. Acad. Bras. Ciênc. [online]. 2016, vol.88, suppl.1, pp.503-516.

SUNE, A.D.; FRANKE, L.B.; SAMPAIO, T. G. Efeitos do condicionamento osmótico na qualidade fisiológica de sementes de Adesmia latifólia (Spreng.) Vog. Revista Brasileira de Sementes, v.24, n.1, p.18-23, 2002. 